Economía, Sociedad y Territorio, vol. vIII, núm. 27, 2008, 769-798

\title{
Procesos y actores en la conformación del suelo urbano en el ex lago de Texcoco
}

\section{Processes and agents in the conformation of the urban land in the former Texcoco Lake}

\author{
Maribel Espinosa-Castillo*
}

\begin{abstract}
The Texcoco Lake has been the object of a number of actions that have caused its desiccation. From Colonial times, near its surroundings, there has been a number of works such as drainage setting, area delimitation and fractioning as well clandestine sells and purchases which eventually have made the land suitable for conurbation with Mexico City. In this process a number of economic, political and social agents intervened in such a way that the desiccation and change in the usage of land (from rural to urban) can be explained as socially induced. In this paper we study the transformation of the Texcoco Lake into the most densely populated urban area in Mexico City from a geographical, social and historical perspective.
\end{abstract}

Keywords: Texcoco Lake, Ecatepec, Nezahualcoyotl, urbanisation, social construction.

\section{Resumen}

El lago de Texcoco ha sido objeto de diversas acciones que lo han conducido a su desecación. Desde la época de la Colonia, en sus alrededores se dieron obras de desagüe, deslindes, fraccionamientos y ventas clandestinas que lo condujeron finalmente a ser terreno propicio para la conurbación con la ciudad de México. En dicho proceso incidieron e intervinieron, diversos actores económica, política y socialmente de manera que el proceso de desecación y cambio de uso de suelo (de rural a urbano) fue un proceso socialmente construido. En este artículo se aborda -desde una perspectiva geográfica, social e histórica- la transformación del lago de Texcoco en el área urbana más densamente poblada de la ciudad de México.

Palabras clave: lago de Texcoco, Ecatepec, Nezahualcóyotl, urbanización, construcción social.

"Instituto Politécnico Nacional, Correo-e: escasmar@hotmail.com, mespinosac@ipn.mx. 


\section{Introducción ${ }^{1}$}

Mucho se ha escrito sobre el proceso de urbanización de la Zona Metropolitana de la Ciudad de México (ZMCM), una urbe que ha sobrepasado el Distrito Federal y llevado sus límites a territorios del Estado de México; sin embargo, el área nororiente se ha estudiado poco. Esta zona de la ciudad se identifica claramente; la distingue su medio natural altamente transformado, la fuerte densidad poblacional, el gran número de problemas sociales que viven sus pobladores y las frecuentes dificultades urbanas a las que se enfrentan.

En numerosos estudios se habla de que la urbanización anárquica de la ciudad de México se debió a múltiples factores, desde las migraciones a la capital del país y la consecuente necesidad de vivienda, pasando por el beneplácito de las empresas inmobiliarias, hasta la complacencia de los actores políticos. Sin embargo, son pocos los trabajos que mencionan de manera específica cómo diversos actores ocuparon, delimitaron, construyeron y se apropiaron de los desecados terrenos del ex lago de Texcoco.

Los actuales municipios de Ecatepec y Nezahualcóyotl, nuestra área de estudio (mapas I y II), comparten elementos históricosociales que los unen e identifican. Este encuentro tiene su inicio en el origen común que tuvieron las colonias del ex vaso de Texcoco, en la desecación de la cuenca de México y en procesos similares de urbanización. De ahí la necesidad de considerar ciertos procesos y actores a fin de comprender la naturaleza de esta área urbana y la dimensión de los problemas que vive hoy en día.

Por ello, el objetivo del presente ensayo es mostrar el cambio geográfico social que se dio y cómo participaron diversos actores en el inicio del proceso de urbanización en el área más densamente poblada en la zona conurbada de la ciudad de México, los terrenos del antiguo lago de Texcoco.

\section{La cuenca de México y el lago de Texcoco}

El lugar donde se asientan los actuales municipios de Ecatepec y Nezahualcóyotl fue parte del antiguo lago de Texcoco y actual-

\footnotetext{
${ }^{1}$ En el presente trabajo, cuando hablamos de los terrenos del ex lago de Texcoco o ex vaso de Texcoco, nos referimos a los terrenos que conformaron el vaso del lago que fueron divididos en vi zonas y destinados al uso urbano habitacional.
} 


\section{Mapa I}

Localización del área de estudio en la ZMCM

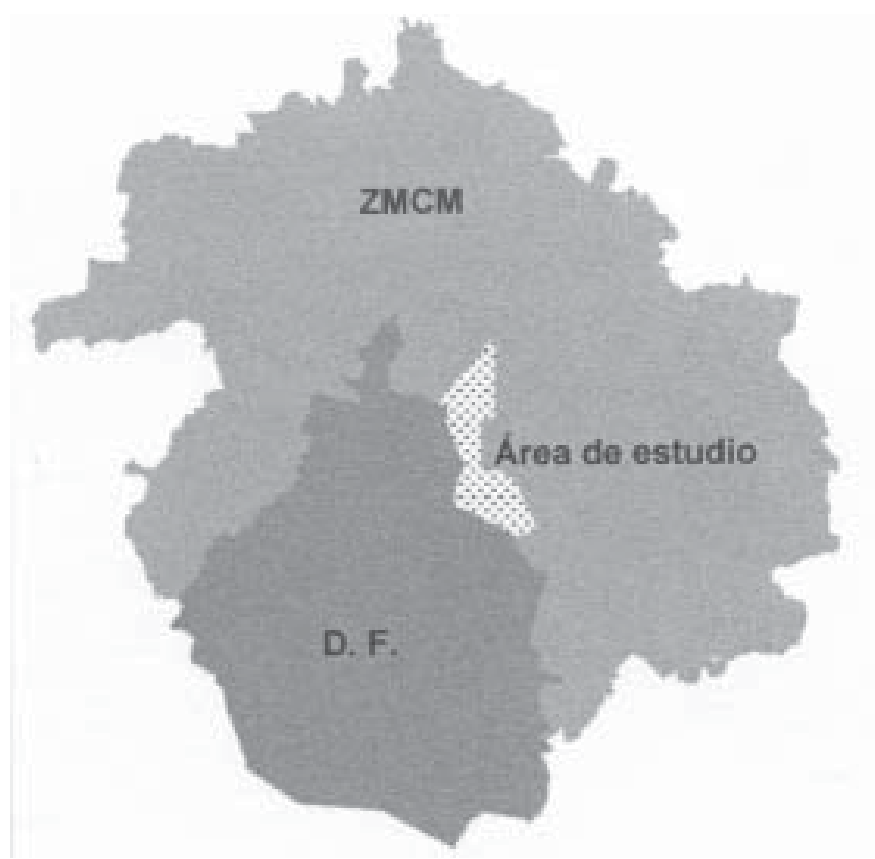

Fuente: Lizbeth Guarneros Avilés y Maribel Espinosa Castillo, elaboración propia con cartografía oficial y contorno de la ZMCM del INEGI.

mente es parte de la ZMCM. $^{2}$ La desecación de este lago se encuentra fuertemente ligada al proceso de crecimiento de la ciudad capital y su área conurbada; de ahí la necesidad de conocer la evolución de desecación de la cuenca.

Históricamente, los asentamientos humanos que se localizaron en la cuenca de México tuvieron una íntima convivencia con el agua. Desde la época prehispánica, en la cuenca se formaba un sistema de lagos, resultado de las corrientes fluviales que bajaban de las montañas, este sistema lacustre formó una cuenca endorreica, es decir, un área que no tenía salidas naturales de

${ }^{2}$ La Ley Orgánica de la Administración Pública del Distrito Federal señala en su artículo $8^{\circ}$ que la ciudad de México es el Distrito Federal (DF), sin embargo, en función de que la bibliografía y los estudios sobre la ciudad la consideran una entidad espacial conformada por el Distrito Federal y el área urbana continúa sobre el Estado de México, y de que es difícil comprender y enfrentar los problemas urbanos del Distrito Federal sin tomar en cuenta el área urbana de los municipios conurbados, se considera área urbana y ciudad de México como la misma unidad espacial (Gaceta Oficial del Distrito Federal, www.setravi.df.gob.mx/leyes/pdf/ley_organica.pdf). 


\section{Mapa II \\ Área de estudio}

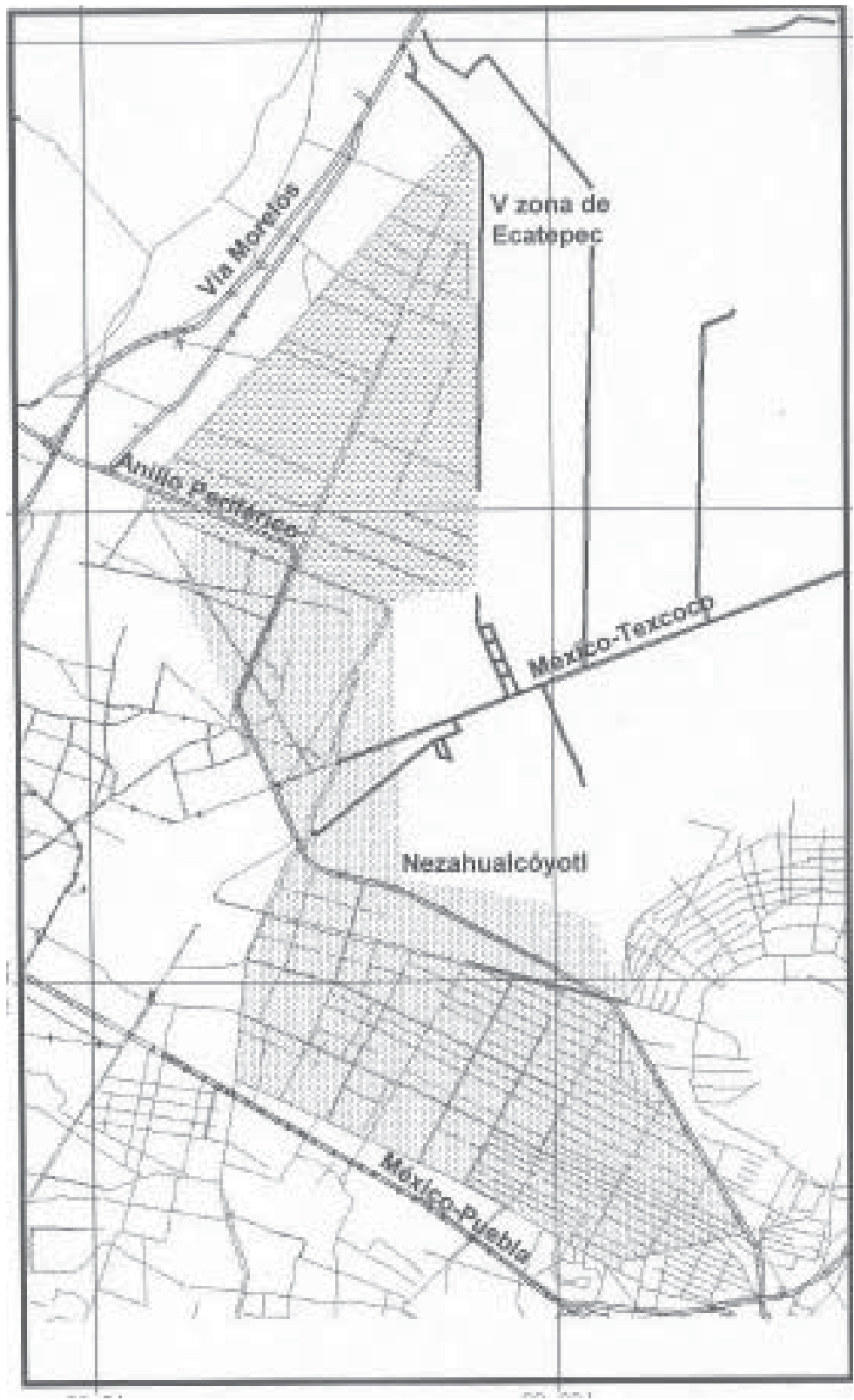

Fuente: Lizbeth Guarneros Avilés y Maribel Espinosa Castillo, elaboración propia con cartografía oficial del INEGI. 


\section{Mapa III}

El lago de Texcoco y la ciudad de México

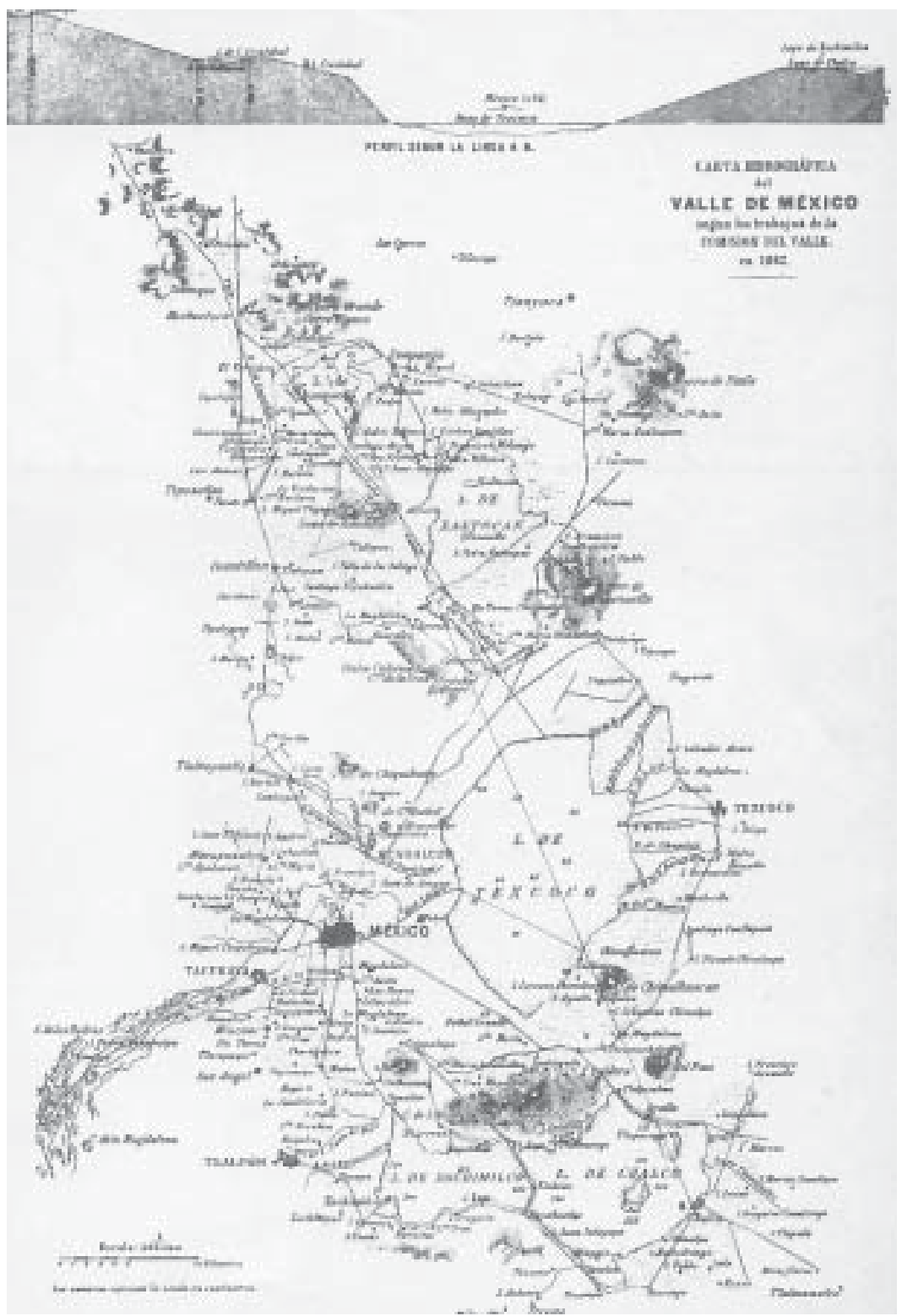

Fuente: Comisión del Valle (1862). 
agua; por eso su gran extensión y capacidad de almacenamiento. ${ }^{3}$ Los lagos que formaban parte de este sistema hidrológico eran: Zumpango, Xaltocan, Texcoco, México, Chalco y Xochimilco (mapa 3).

El lago de Texcoco era el mayor de todos. Tenía una extensión de alrededor de $700 \mathrm{~km}^{2}$ debido a que se localizaba en la parte más baja (aproximadamente a 2,235 msnm), recibía el agua de los otros lagos y era extremadamente salino. Los lagos de Xochimilco y Chalco se ubicaban unos metros más arriba que el de Texcoco y, gracias al flujo de numerosos arroyos, sus aguas eran dulces y los cubría vegetación flotante. Zumpango y Xaltocan también estaban a mayor altura que el lago de Texcoco, por lo que descargaban en él sus aguas en época de intensas lluvias; en consecuencia, eran más salobres que Xochimilco y Chalco, pero menos que Texcoco (Valek, 2000: 18).

Los primeros asentamientos humanos se localizaron en los márgenes de las lagunas o en las pocas porciones elevadas cercanas al área de tierra firme. Por estas circunstancias, además de otros motivos económicos y políticos, la urbe de México-Tenochtitlan se tuvo que planear y urbanizar a partir de algunos islotes y comenzó a generar o crear tierra firme sobre el lago. La técnica constructiva de chinampas ayudó a expandir la ciudad, lo que representó el medio idóneo para obtener tierra firme, así como una forma de producir alimentos y de embellecer la ciudad.

Para controlar las constantes inundaciones que se presentaban en la ciudad de México-Tenochtitlan, los antiguos mexicanos pensaron en la construcción de diques y canales que les permitieron controlar los niveles de agua en las lagunas. Con este objetivo se mandó construir un dique que separó las aguas dulces de la laguna de México de las aguas saladas de la laguna de Texcoco; obra conocida como el albarradón de Nezahualcóyotl y con la cual se controlaban las inundaciones y garantizaba la productividad agrícola en las chinampas. ${ }^{4}$

\footnotetext{
${ }^{3}$ La cuenca "se encuentra limitada al norte por las sierras de Tezontlalpan, Tepotzotlán y Pachuca, que se caracterizan por ser las menos elevadas, pues sólo alcanzan una altura máxima de 3,000 m. Al sur de la cuenca se levantan las sierras del Ajusco y de Chichinautzin, que alcanzan una altitud de 3,800 m a 3,900 m. En el oriente el límite está constituido por la Sierra Nevada, en donde sobresalen por su altitud los picos nevados del Popocatépetl y del Iztaccíhuatl con 5,747 y 5,286 m de altura, respectivamente. Por último, hacia el poniente se localizan las sierras de las Cruces, Monte Alto y Monte Bajo, de hasta 3,600 m” (Valverde y Aguilar, 1987: 20).

${ }^{4}$ El albarradón de Nezahualcóyotl, atribuido al rey de Texcoco, tenía una extensión de $12,000 \mathrm{~m}$ de largo y $20 \mathrm{~m}$ de ancho. Era un dique, muro o calzada formado con piedra, arcilla y empalizado. Es una de las obras hidráulicas más importantes de la época mesoamericana que habla de la incidencia del ser humano sobre el medio.
} 
La construcción del albarradón evidenció una circunstancia que caracterizó al territorio en ese momento y que hasta nuestros días se mantiene. La obra dividía la laguna, separaba el agua dulce -favorable para la productividad agrícola y el consumo humano- del agua salada de Texcoco, poco útil para la agricultura pero favorable para la pesca y la conservación de fauna acuática y silvestre. ${ }^{5}$ Cuando los antiguos mexicanos lograron controlar y convivir con la naturaleza de los lagos, a través del Albarradón, construyeron una forma de uso del territorio inundable, por tanto, un territorio para habitar.

Cuando llegaron los españoles la relación con el medio ambiente cambió, a pesar de que la ciudad colonial se erigió sobre la base de la misma ciudad mesoamericana, pues el tratamiento que los españoles dieron a la ciudad fue completamente diferente. Con la ciudad colonial se impuso una nueva forma de pensar y construir la ciudad, algunos ríos se utilizaron como zanjas de desagüe de aguas usadas que iban a dar a las lagunas; la tala de árboles para construir palacios, elaborar muebles o como combustible se hizo una práctica incontrolable, lo que llevó a que los ríos fueran desviados, secados o contaminados. Todo ello afectó el clima, la fisonomía y la productividad de la cuenca y fue el inicio del proceso de cambio del sistema hidrológico.

El drenado de los lagos se inició a los pocos años de la llegada de los españoles. Se cerraron las calles de agua, comenzó el drenado de la cuenca así como un sistema constructivo sobre territorio seco. Una de las primeras obras fue un canal entre Xaltocan y Zumpango que empezó a sacar el agua de los lagos, además de la construcción del albarradón de San Lázaro en 1555 para el desalojo de la cuenca; sin embargo, esta obra no fue suficiente y la ciudad siguió viviendo en constante zozobra por las inundaciones.

Durante el Virreinato el agua fue un obstáculo en la consolidación de la sociedad novohispana, a lo largo de toda la Colonia se sucedieron impresionantes inundaciones en la ciudad de México. La primera inundación severa se dio en 1555, a la que siguieron otras en 1580, 1604, 1607 y de 1624 a 1631 que dejaron a la ciudad anegada por mucho tiempo.

En 1607 el gobierno virreinal emprendió trabajos para desaguar definitivamente las lagunas. El ingeniero Enrico Martínez

${ }^{5}$ Existen diferentes tipos de lagos debido a la constitución química de los suelos que los contienen, de ahí que existan lagos salados que contienen sales; ácidos, que contienen sulfatos, alcalinos que contienen carbonatos y lagos de borax que contienen boratos. 
fue el encargado de presentar un programa para drenar los lagos de México. Después de varias propuestas (del mismo Enrico Martínez) se decidió drenar solamente el lago de Zumpango a través de una galería subterránea en el sitio de Nochistongo. "El plan, entonces, era construir un túnel a través de las montañas, en la esquina noroeste de la cuenca, cerca de Huehuetoca, y dirigir el exceso de agua en él mediante una serie de canales" (Valek, 2000: 52). Sin embargo, las inundaciones continuaron y a partir de 1629 las discusiones, propuestas y obras relativas a la forma de desecar los lagos fueron permanentes.

Otras acciones tendentes a evitar inundaciones fueron: convertir el túnel de Huehuetoca en tajo abierto (1675), la edificación del albarradón de San Mateo (1747) y la construcción de los canales de Guadalupe (1796) y de San Cristóbal (1798) para drenar los lagos Zumpango y San Cristóbal. Con estas obras, los lagos poco a poco se separaron, redujeron su extensión y afloraron las orillas de tierra firme.

El constante movimiento de agua en el lago de Texcoco acarreaba tierra hacia el fondo del mismo, lo que provocó que el lecho se elevara y cuando las lluvias lo inundaban su mayor altura lo desbordaba e inundaba la ciudad; de ahí que su cercanía con la ciudad de México fuera uno de los elementos que motivaron su desecación. Con la desecación se perdió su hermosura y fue naciendo un escenario único en la cuenca y característico en la urbanización de la ciudad de México: un valle seco, de sales e insalubre. ${ }^{6}$

Si bien durante la época colonial los esfuerzos por desecar los lagos fueron constantes, el drenado de éstos y de la cuenca no se concluyó; fue hasta mediados del siglo XIX cuando el ingeniero Francisco de Garay dirigió los trabajos de reparación de Mexicaltzingo al tiempo que proponía abrir un gran canal y desecar los lagos. Con el mismo objetivo, M. L. Smith propuso abrir un tajo en Tequixquiac, sin embargo, fue hasta 1865 cuando Garay, como director del desagüe del Valle de México, comenzó los trabajos de drenaje en tres partes: un tajo abierto de Texcoco a Zumpango; un túnel de Zumpango a Tequixquiac y el tajo de Te-

${ }^{6}$ En 1840 Madame Calderón de la Barca conoció los lagos de México, al respecto escribió "los límites de los dos lagos, el de Zumpango y el de San Cristóbal, al norte del Valle se habían reducido, y el lago de Texcoco, el más hermoso de los cinco, dejó de recibir sus derrames. De este modo ha disminuido el peligro de las inundaciones; pero también ha disminuido el agua y la vegetación, y los suburbios de la ciudad, cubiertos una vez por el hermoso verdor de sus jardines, no presentan en el día sino una costra de sales eflorescentes" (Calderón, 2003: 105). 
quixquiac. Posteriormente, en 1893, se terminaron las obras del tajo y del túnel de Tequixquiac y en 1900 el presidente Porfirio Díaz inauguró el gran canal. ${ }^{7}$ Sin embargo, en los primeros años del siglo xx las obras mostraron sus primeras fallas, cuando en la época de lluvias la ciudad se volvió a inundar; la búsqueda de soluciones a este problema de la ciudad de México continuaba.

La Comisión Hidrográfica de la Secretaría de Comunicaciones y Obras Públicas en 1906 elaboró un plano en el que se muestra la trayectoria del canal del desagüe del lago de Texcoco, vía que iniciaba desde el centro mismo de dicho lago. Años después, en la década de los treinta, se construyó la prolongación sur del gran canal de desagüe, se instalaron colectores y se hicieron reparaciones al sistema de drenaje. Paralelo al proceso de desagüe, la parte este y sur del lago de Texcoco se destinó a conservar agua y crear una superficie para mejorar el suelo, abrir canales y drenar el territorio.

En 1934 se iniciaron las obras del nuevo túnel de Tequixquiac, las cuales se terminarían en 1954, junto con otros proyectos para controlar los flujos de agua y encauzar y entubar la mayoría de los ríos. En la década de los cincuenta el drenaje de la ciudad siguió siendo insuficiente, de ahí que en 1954 se determinara crear el nuevo túnel de Tequixquiac a través de la barranca de Acatlán, el cual ayudó a drenar el agua de la cuenca, así como continuar creando presas y entubando ríos.

En 1967 se aprobó el proyecto del sistema de drenaje profundo "con un presupuesto de 5,400 millones de pesos y 136 kilómetros" de longitud (Valek, 2000: 88), el cual trabajaría por gravedad a grandes profundidades para no tener problemas de hundimiento e inundaciones. Fue en los últimos 50 años cuando los lagos y ríos prácticamente desaparecieron y la extensión del lago de Texcoco fue disminuyendo lentamente. ${ }^{8}$

De esta manera, el sistema lacustre ha ido desapareciendo por obras de drenaje, entubado de ríos y manantiales, explotación y contaminación de mantos acuíferos, deforestación y ero-

\footnotetext{
7 "El gran canal, con 47 kilómetros [...], drena las partes bajas de la ciudad mediante 12 plantas de bombeo y recibe agua de los ríos: los Remedios, San Javier, Tlalnepantla y Churubusco, así como del lago de Texcoco. El sistema, que puede alcanzar una capacidad de $100 \mathrm{~m}^{3}$ por segundo, descarga sus aguas -a través de dos túneles de Tequixquiac- en el río Salado y la cuenca del río Tula, donde parte de esta agua se destina a la irrigación de campos de cultivo en el estado de Hidalgo" (Valek, 2000: 89).

${ }^{8}$ En 1608 Enrico Martínez consideraba una extensión de los lagos en 41,000 ha; en 1861 de acuerdo con la Comisión del Valle había 27,217 ha; la Comisión Hidrográfica calculaba ésta en 26,691 ha para 1904; y de 14,000 ha en 1966 según la SRH-GGOVM (Nacional Financiera-sHCP, 1969: 12).
} 
sión de los suelos; todo ello paralelo al incremento de la población y al uso de suelo urbano. Esta incidencia sobre el sistema hidrológico proporcionó grandes extensiones de tierra a los habitantes cercanos a ellas, los cuales iban utilizando y apropiándoselas para uso urbanos.

Así, a partir de la década de los cuarenta comenzó a cambiar intensamente el uso de suelo en los terrenos del desecado lago de Texcoco. La cercanía con la ciudad y la posibilidad de utilizarlos como suelo agrícola o urbano incentivó un proceso de venta de tierras ganadas al lago. El lecho de éste proporcionó los territorios donde se asentaron los pobladores migrantes durante las décadas de los cincuenta, sesenta y setenta, territorio que actualmente forma parte de los municipios de Ecatepec y Nezahualcóyotl.

\section{Acciones y actores en la formación de suelo urbano9}

A principios del siglo $\mathrm{xx}$, los terrenos que surgieron de la desecación del lago de Texcoco representaban un problema de salud para la ciudad de México debido a las tolvaneras de tierra y sal que ahí se originaban. Los primeros gobiernos revolucionarios se ocuparon de deslindar el lecho del lago y planearon proyectos agrícolas (1919) y piscícolas (1921), con el fin de resolver el problema de las tolvaneras. Si bien esos proyectos eran loables, el proceso que se dio en el deslinde, bonificación y venta de los terrenos fue un caos, debido a la falta de claridad en la política urbana que se seguiría en el crecimiento de la ciudad; esto se hizo evidente en los diversos procesos de deslinde y venta que sufrió el territorio.

En la medida en que el lago de Texcoco se iba desecando, las tierras ganadas se deslindaron y otorgaron a comunidades o personas para su uso agrícola, o arrendadas para su lavado y bonificación. Al principio sólo se habían repartido las orillas del lago, sin embargo, el fraccionamiento y deslinde de los terrenos era el inicio de la venta para futuro uso urbano (mapa IV).

En 1922 se emitieron los primeros acuerdos de arrendamiento y se declaró de utilidad pública la bonificación de lotes del ex vaso de Texcoco. Dicha bonificación estaba planeada con el fin de destinar el territorio para uso agrícola, sin embargo, desde el

\footnotetext{
${ }^{9}$ Desde 1906 la Secretaría de Comunicaciones y Obras Públicas identificó el vaso de Texcoco dentro del perímetro del lago de Texcoco, de ahí que ambos conceptos se refieran al mismo territorio. La desecación del lago no fue total, una pequeña parte de él subsiste.
} 


\section{Mapa IV}

Terrenos comprendidos dentro de la zona desecada del lago de Texcoco

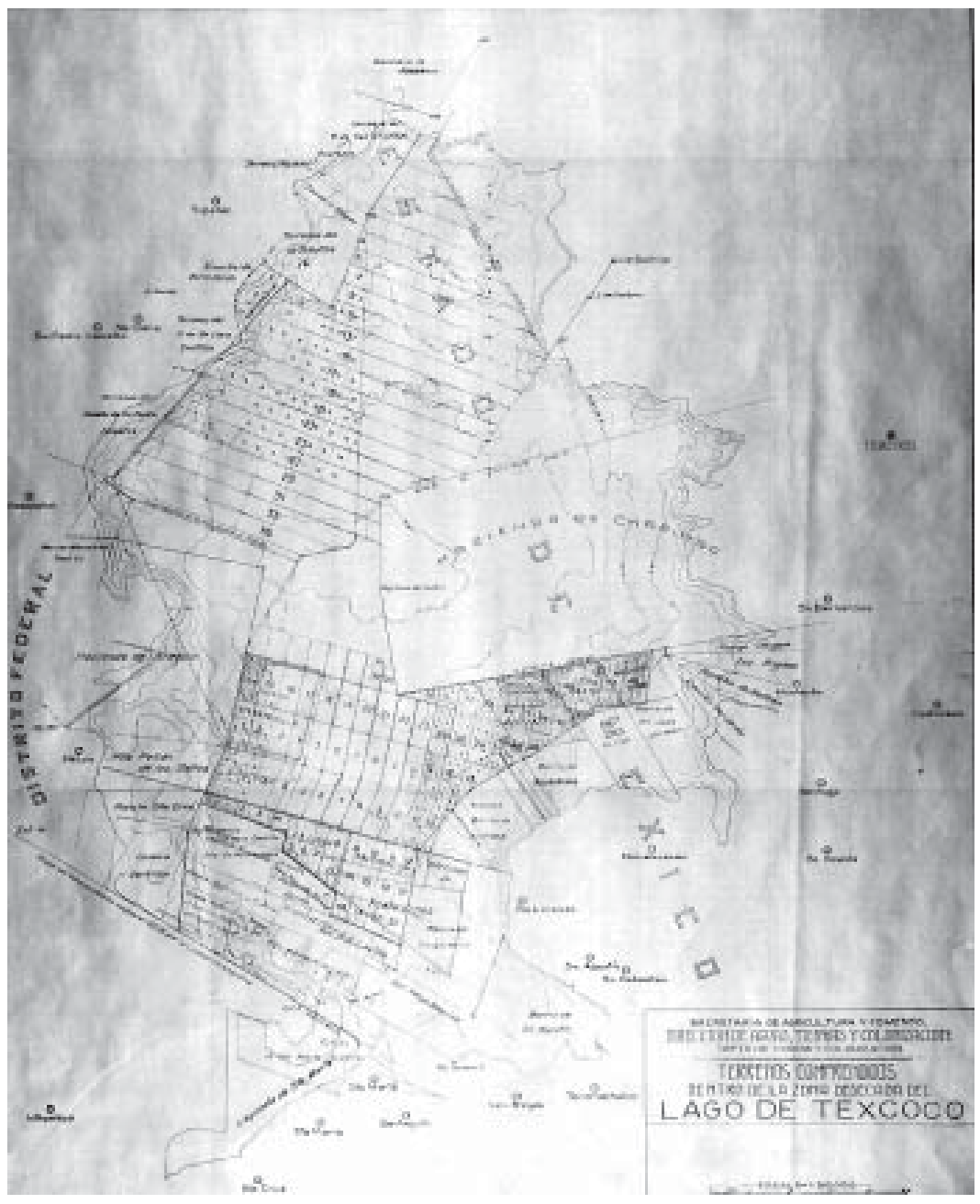

Fuente: Secretaría de Agricultura y Fomento, Dirección de Aguas, Tierras y Colonización, Departamento de Tierras y Colonización, escala 1:50 000, Mapoteca Manuel Orozco y Berra. 
principio la salinidad del suelo mostró las pocas posibilidades de la tierra para ese uso.

Por otro lado, a fines de la década de los veinte y principios de los treinta los gobiernos federal y el estatal propusieron otras acciones. Por un lado, en 1929 el gobierno del presidente Emilio Portes Gil señaló que la bonificación y fertilización del lecho del lago la podían hacer particulares, y desde ese año el gobierno del Estado de México empezó a ceder derechos de posesión de terrenos. Por otro lado, había preocupación de la federación sobre la utilización de los terrenos del lago y la salubridad de la ciudad; de ahí que desde diversas instancias se levantaran voces sobre el problema que significaba el ex lago y se plantearon algunos proyectos de integración de este territorio a la ciudad de México.

Dentro de esos proyectos se encontraba el del Parque Agrícola de la Ciudad de México (1930), en el que se proponía utilizar los terrenos del ex vaso de Texcoco para fines agropecuarios, bonificando y aprovechando los terrenos desecados y controlando el movimiento de las aguas de la cuenca de México. El ingeniero Ángel Peimbert y los arquitectos Luis MacGregor y Augusto Petricioli planearon dicho parque de la siguiente manera:

Para realizar tal fin hemos imaginado un proyecto que haga de los lagos, y con especialidad el de Texcoco, una dependencia de la Ciudad de México; que sea para ésta como un gran Parque Agrícola donde la pequeña agricultura se desarrolle intensivamente, donde encuentren aplicación las industrias derivadas, donde la propiedad se halle ya subdividida, donde encuentren ocupación noble y lucrativa millares de familias (Peimbert et al., 1930: 20).

En el contexto de la planificación del valle de México, el proyecto consideraba una gran área agrícola para la ciudad, casi toda el área oriente, incluidos los terrenos del desecado lago de Texcoco. El parque se observaría como un abanico territorial integrado por caminos o varillas que partían de cerca del Peñón de los Baños, que sería sede o puerto para distribuir las mercancías y productos a la ciudad. Esos caminos formarían cinco sectores que serían divididos en parcelas de 25 ha, esta división formaría una retícula de caminos de tierra y canales de agua para facilitar su movimiento en todo el sistema y formar un vaso regulador. Los caminos estarían unidos por uno de circunvalación alrededor del parque que comunicaría a todos, y junto a éste también un canal navegable. Al centro se proponía la Ciudad del Lago que cumpliría funciones de administración, descarga y almacenamiento de los productos agrícolas. 
La idea de integrar este territorio a la ciudad era evidente cuando se proponía convertirlo en un barrio de la Ciudad de México, el proyecto señalaba que:

Ya se ha dicho que el punto de convergencia de las comunicaciones es la zona del Peñon de los Baños. Este sitio, interesantísimo, hoy en abandono casi absoluto, será un puerto en el que se concentrarán para distribuirse todas las mercancías y productos que lleguen del Parque Agrícola y de las comarcas ribereñas. Se formará en torno de la colina una dársena con edificios adecuados al almacenamiento y tráfico de esos efectos. Seguramente se formará en sus aledaños un conglomerado de población, como un nuevo barrio de México. Se aprovecharán sus manantiales de aguas calientes y cargadas de sustancias minerales para el establecimiento de una estación de baños de placer y terapéuticos modernamente acondicionada. Se formarán parques, paseos; el cerro será motivo de utilizaciones pintorescas y se le volverá la vida a ese pequeño poblado que agoniza ahora injustificadamente en medio de la incuria y de la sed. A este punto concurrirá y en él descargara sus aguas, el antiguo Canal de la Viga, vía fluvial de tráfico tan intenso, cuya terminal se ha llevado en la actualidad muy lejos del corazón de la ciudad, después de haber sido, en otros tiempos, importante factor de abastecimientos de México (Peimbert et al., 1930: 23).

Así, el Parque Agrícola se transformaría en una fuente de bienestar y salud, fomentaría las actividades productivas agrícolas, el empleo y los ingresos de familias y de la hacienda pública, la pequeña propiedad rústica $\mathrm{y}$, en general, mejoraría las condiciones de vida de la capital.

Cabe señalar que el proyecto del Parque Agrícola debió haberse considerado en el Plano Regulador del arquitecto Carlos Contreras de $1933^{10}$, ya que en esos años el presidente Pascual Ortiz Rubio creó la Comisión Técnica del Parque Agrícola de la Ciudad de México, la cual se encargó de presentar “un importante álbum del proyecto de bonificación de las tierras del vaso del lago de Texcoco" bajo la dirección del Ingeniero Ángel Peimbert, y quien generó algunas obras en 1933 (Franco: 1948: 219).

Contrario a lo anterior, el gobierno del Estado de México tenía un destino diferente para los terrenos del ex lago. Como se señaló, desde diciembre de 1929 existía la posibilidad de ceder

\footnotetext{
${ }^{10}$ Carlos Contreras, el gran planificador de principios de siglo xx en México, fundó la revista Planificación (1927), organizó el Primer Congreso Nacional de Planeación (1930), elaboró el Plano Regulador de la Ciudad de México (1933), propuso la Comisión Nacional de Planificación, impulsó la Ley sobre la Planificación de Monterrey; influyó en la Ley sobre Planeación General de la República (1930) y en la Ley de Planificación y Zonificación del Distrito Federal y Territorios de Baja California (1933) y propuso el Plan de Desarrollo de la Ciudad de México (1935) (Sánchez, 2002).
} 
los terrenos en bonificación y transferirlos a particulares, y así se hizo según lo muestran los contratos celebrados entre la Secretaría de Agricultura y Fomento y los ciudadanos, los cuales se publicaron en la Gaceta del Gobierno del Estado de México (GCEM) en 1931. En ese año se dio a conocer la lista de los arrendatarios de terrenos del ex lago de Texcoco, en la que se precisa que se bonificaron 532.75 ha de terreno (GCEM, 1931). ${ }^{11}$

El deslinde y fraccionamiento de terrenos no quedo ahí, y en 1932 el gobernador del Estado de México, Filiberto Gómez, vinculó el deslinde y venta de terrenos del ex lago de Texcoco a personalidades de la política nacional y militares de la siguiente manera:

Varios señores generales [...] jefes de operación, jefes de departamento de la Secretaría de Guerra y Marina y más de cien generales jefes del Ejército Nacional así como un numeroso núcleo de altos empleados federales y de algunos particulares [...] han adquirido alrededor de 7,000 ha de terrenos ganados por la desecación del antiguo vaso del lago de Texcoco (García y Gutiérrez, 1999: 96).

De esta forma se vendían lotes de 40 ha, una persona podía adquirir hasta dos lotes, el valor del terreno era de $\$ 1.00$ por hectárea, precio que se había fijado para facilitar el acomodo de los lotes. ${ }^{12}$ Los precios de venta eran irrisorios y a ello se sumaba el costo de un $\$ 1.00$ peso que se cobraba por impuesto predial, tarifa que se haría efectiva en los siguientes 20 años. El gobernador precisó que con la adquisición de los terrenos, aquellos personajes participaban en las obras de rescate de los mismos, a la vez que definían el uso que se le había asignado de facto al territorio: propiedad particular y de uso urbano.

Cabe señalar que entre los militares, empleados de gobierno y personalidades que adquirieron algunos de esos terrenos, a muy buen precio, sobresalen: el ingeniero Peimbert y los arquitectos

\footnotetext{
${ }^{11}$ Según los contratos celebrados entre la Secretaría de Agricultura y Fomento y los particulares a quienes se arrendó el lecho del lago para su bonificación, ésta consistía, según la cláusula décima quinta, en lo siguiente: “...se considera bonificado el lote cuando después de haber sido lavado el terreno, se encuentre bajo cualquier cultivo agrícola en el momento de la inspección" (GCEM, 1931).

${ }^{12}$ El precio de los terrenos fue bajando poco a poco, en 1919 la Secretaría de Agricultura y Fomento arrendaba los terrenos a \$ 60.00 oro la hectárea, para 1921 el precio se reduce a $\$ 30.00$ oro, se dijo que para fomentar la agricultura; finalmente, en 1929 el presidente Emilio Portes Gil en un acuerdo presidencial decreta que el precio de la ha es de $\$ 1.00$ a fin de fomentar la agricultura y mejorar las condiciones de salubridad (García Luna, 1990).
} 
MacGregor y Petricioli, la señora Josefina Ortiz de Ortiz Rubio, los generales Ignacio Leal Brown, Francisco Mújica y Lázaro Cárdenas, así como el coronel Leopoldo Treviño.

El uso que se le quería dar al suelo del ex lago quizá pudo leerse mejor cuando el propio gobernador Gómez señaló la necesidad de exención de impuestos de todos los terrenos comprendidos en la cota 7.10 "y exención general en la zona IV para la construcción de la Ciudad Radial" que estaba proyectada para urbanizarse lo antes posible (García y Gutiérrez, 1999: 97). Ésta fue la segunda ocasión en que se señalaba la intencionalidad de crear un espacio urbano; la primera fue la Ciudad Lago del proyecto del Parque Agrícola de Peimbert; ambas ciudades pudieron haber sido parte del mismo proyecto.

Con estas diversas y contradictorias acciones en los ámbitos federal y estatal, no quedaba claro si los propietarios de los terrenos otorgados eran quienes aparecieron en la GGEM de 1931 y que hicieron sus contratos de bonificación con la Secretaría de Agricultura y Fomento; los coroneles, generales, políticos y profesionales señalados en el deslinde de 1932; o ambos grupos. Lo que sí se observa es que tanto el gobierno estatal como el federal tenían una intención contraría a lo que decían sobre el uso agrícola que se le tendría que dar al lago.

Las contradicciones sobre la propiedad del suelo se acumulaban de tal manera, que para 1933 fue necesario actualizar el deslinde, localización y levantamiento de los terrenos ubicados en el ex lago de Texcoco a través de una Comisión Oficial Deslindadora. En marzo de ese año la comisión señaló lo siguiente:

La Comisión Oficial Deslindadora de los Terrenos del Vaso de Texcoco, nombrada por acuerdo de la Secretaría de Agricultura y Fomento, de fecha 15 de junio [...] está procediendo en la actualidad al deslinde, localización y levantamiento de los terrenos ubicados dentro del vaso del referido lago, y comprendidos dentro de la curva de acotación 7.10 metros sobre el plano de comparación de la nivelación general del Valle de México (GCEM, 1933).

La venta a bajo precio de los terrenos, la falta de precisión sobre la propiedad de la tierra y las constantes declaraciones y proyectos de planificar el área es lo que acompaña a los terrenos del ex vaso de Texcoco en los siguientes años por el camino de la confusión y la anarquía. Los esfuerzos de los gobiernos federal y estatal, sin duda, estaban dirigidos a utilizar los terrenos del ex lago, sin embargo, las acciones para darle un uso agropecuario y piscícola dieron paso a las acciones de venta de terrenos a parti- 
culares, y de esa manera el incremento de la propiedad individual aumentó la cantidad de tierra que se dispondría para el mercado inmobiliario irregular, facilitando con ello la urbanización del lecho del lago.

Es importante señalar cómo se llevó a cabo el deslinde y levantamiento limítrofe de los terrenos del desecado lago de Texcoco. ${ }^{13}$ El vaso del lago se delimitó a partir de la cota 7.10 del terreno, el área que se fraccionó fue la poniente, dividida a su vez en VI zonas. El número de éstas se asignaron del I al VI, en orden de sur a norte, de manera que la zona II quedó al sur y la VI al norte. Las zonas I, II, III y IV corresponden a lo que actualmente es el municipio de Nezahualcóyotl, la IV zona se distingue hoy porque es la parte norte de Nezahualcóyotl; la v corresponde a un área triangular que forma parte del municipio de Ecatepec, el límite poniente de esta área corre paralela al Gran Canal del desagüe, a una distancia de entre 500 metros y un kilómetro en su extremo sur y norte, respectivamente, y al oriente colinda con los terrenos del ex lago de Texcoco al borde del antiguo canal de desagüe del lago de Texcoco. Una parte de la zona vi se localizó al norte del territorio actual del municipio de Ecatepec y otra correspondió al municipio de Atenco; asimismo, el área de El caracol, que eran terrenos de tratamiento de sales que pertenece al municipio de Ecatepec, era parte de la VI zona (plano I).

Así, el municipio de Nezahualcóyotl se constituyó con tierras de las zonas I, II, III y IV del desecado lago de Texcoco, considerando además terrenos en común repartimiento pertenecientes al municipio de Chimalhuacán (De la Torre, 1975: 57); mientras que Ecatepec se quedó con los terrenos de la v zona y parte de la VI. Por eso el área de análisis del proceso de urbanización de los terrenos del ex lago de Texcoco corresponde a esas dos entidades municipales.

Como se señaló, los terrenos desecados fueron intervenidos a principios del siglo $\mathrm{xx}$, deslindados y destinados a uso agrícola o piscícola, arguyendo el cuidado de la salubridad de la ciudad de México. Hasta aquí existía una planificación del territorio, sin

${ }^{13}$ El perímetro del vaso del ex lago lo demarcó la Secretaría de Comunicaciones y Obras Públicas el 30 de abril de 1931, el límite fue hasta la cota 7.10 del lago. Un informe sobre el levantamiento topográfico del lago de Texcoco de 1966 señala que "El presidente Ortiz Rubio [...] confirmó la declaratoria de propiedad nacional de las aguas y cause del lago, fijando como límite de éste la curva de acotación $7.10 \mathrm{~m}$, referida a la tangente inferior del calendario Azteca en su primitiva posición del lugar donde fue encontrado. Es decir, el plano de comparación corresponde a una cota $10 \mathrm{~m}$ debajo de la expresada tangente y la cota $7.10 \mathrm{~m}$ al nivel de aguas máximas normales” (Caneda, 1966). 


\section{Plano I \\ Fraccionamiento de terrenos del ex lago de Texcoco en seis zonas (1932 ca.)}

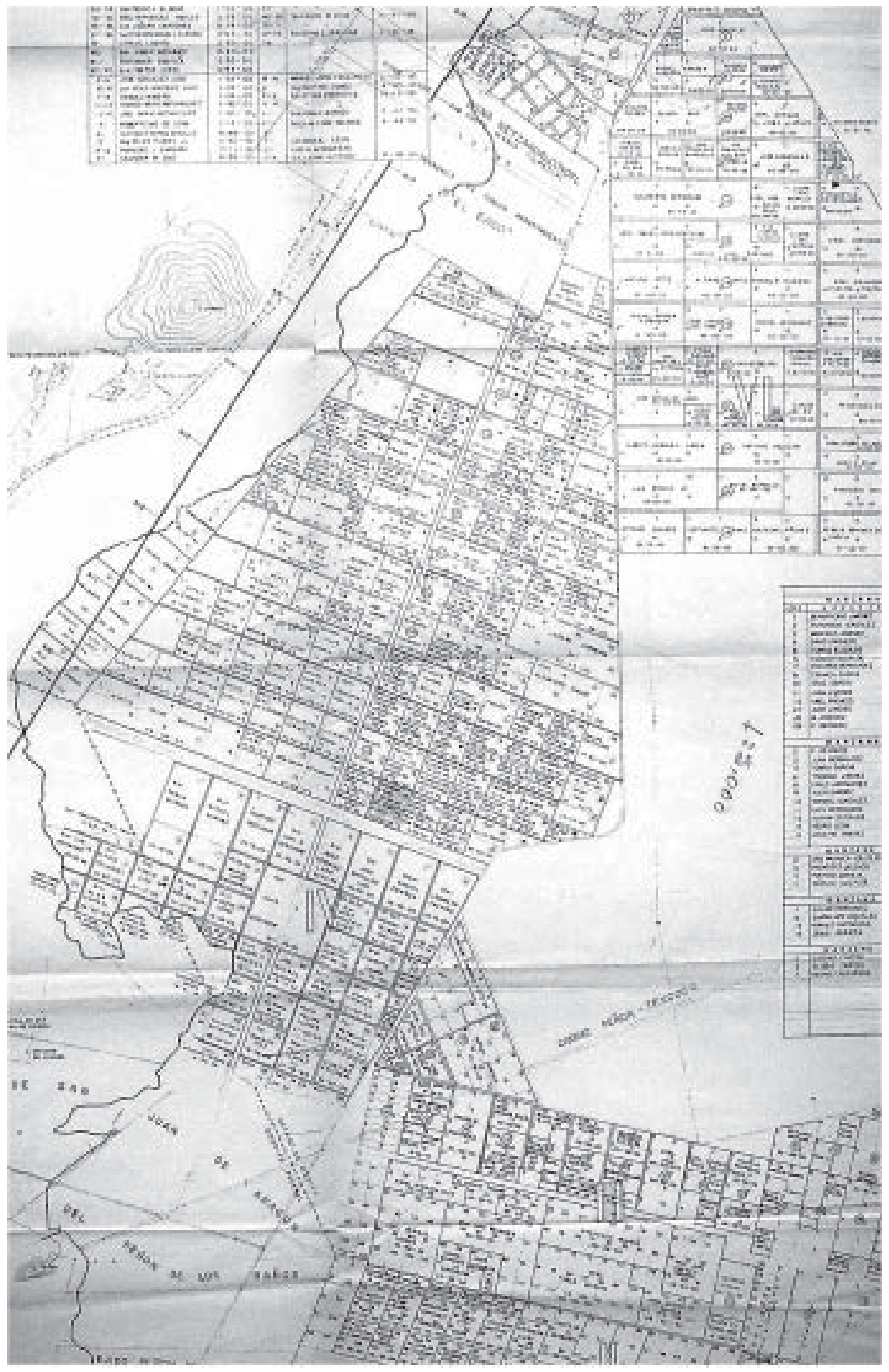

Fuente: Archivo Municipal de Ecatepec de Morelos, México. 
embargo, el proyecto del gobierno del Estado de México se sobrepuso al del gobierno federal, lo que condujo al fraccionamiento y uso urbano de la zona. Una vez que el área desecada se distribuyó -perteneciendo a particulares, militares y burócratas-, no fue bonificada, por lo que se encontró en condiciones propicias para ser fraccionada y destinada a procesos particulares de urbanización de colonias o fraccionamientos irregulares.

Muchos actores y condicionantes intervinieron para que se constituyera en suelo urbano, entre ellos, la incapacidad del Estado para verificar y hacer cumplir la bonificación de las tierras, la demanda de suelo urbano por parte de los migrantes, la oportunidad que vislumbraron algunos fraccionadores para obtener buenas ganancias con la venta de suelo barato, el interés clientelar de algunos políticos y las restricciones para construir fraccionamientos en el Distrito Federal; sin embargo, la disponibilidad de suelo barato, resultado de la desecación del lago de Texcoco, fue la circunstancia originaría para que se diera el proceso de urbanización al nororiente de la ciudad.

\section{La venta irregular del suelo del ex lago}

Para el año de 1942, la Ley de Planificación y Zonificación del Estado de México (LPZEM) regulaba el ordenamiento de los territorios del ex lago, misma que señalaba las funciones que debía cumplir la Junta de Planificación en el desarrollo conjunto de los territorios del estado, y era el máximo instrumento legal de planificación en el Estado de México (GCEM, 1942). En 1944 se reformó su artículo 43 en el que se daban facultades al gobierno del estado para contratar empréstitos necesarios para la ejecución de obras públicas (GCEM, 1944); para 1945 se emitió una Ley de Protección a las Nuevas Construcciones, Fraccionamientos Industriales, Residenciales y Obras de Irrigación en la que se otorgaban franquicias especiales y exenciones a los fraccionamientos industriales, agrícolas y habitacionales que cumplieran los requisitos que las diferentes instancias gubernamentales señalaban, incluida la Junta de Planificación y Zonificación (GCEM, 1945). Es decir, las Juntas de Planificación y Zonificación tenían la facultad de adquirir créditos y otorgar exención de impuestos para fomentar nuevas construcciones, incluidas las de carácter urbano.

Sin embargo, en septiembre de 1948 -cuando ya se encontraban los primeros asentamientos cerca de la carretera a Puebla, en los terrenos del ex lago de Texcoco- el gobierno del estado 
emite dos reformas contradictorias sobre fraccionamiento y venta de lotes. La primera es la adición de los artículos 53 al 58 en la LPZEM en los que se establece que las autoridades gubernamentales no podrán autorizar y ratificar un contrato de compra de lotes, si no se justifica que existe la autorización para venderlos como lo exigía la LPZEM; ${ }^{14}$ además se incluían las sanciones a las que se hacían acreedores quienes violaran dichas normas (GCEM, 1948). ${ }^{15}$ Esto haría pensar en una estricta supervisión de las autoridades del crecimiento de asentamientos humanos en todo el estado, pero no fue así. La segunda reforma fue una adición a la LPZEM en la que se especifican las condiciones en que se daría autorización para la venta de lotes aun cuando el fraccionamiento no cumpliera con los servicios urbanos necesarios (GCEM, 1948). Esta adición autorizaba la venta de lotes cuando el fraccionador depositara un pago en alguna institución de crédito del gobierno como garantía de urbanización. ${ }^{16}$ No se sabe si los depósitos de garantía de urbanización se pagaban o no, lo cierto es que el gobierno del estado autorizó muchos asentamientos humanos irregulares, pues carecían de obras y servicios urbanos mínimos, con enormes evidencias de pobreza y marginalidad.

Es hasta 1958 cuando se emite la Ley de Fraccionamientos de Terrenos del Estado de México (LFTEM), más de diez años después de que iniciara el fenómeno de las invasiones de terrenos y en pleno proceso de conurbación con la ciudad de México. En esta ley se señalaba que los fraccionamientos urbanos no podían ser objeto de venta mientras no concluyeran las obras de urbanización; sin embargo, el proceso de fraccionamiento y venta irregular de terrenos continuaba. ${ }^{17}$

\footnotetext{
${ }^{14}$ El artículo 54 decía: "Los Notarios, Agentes Notariales, Jueces Conciliadores y demás funcionarios ante quienes, conforme a las Leyes, puedan ser ratificados los contratos privados, no autorizarán la ratificación de un contrato de esa especie por el que se enajene por el propietario de un fraccionamiento un lote del mismo, si no se justifica fehacientemente que existe la autorización que para vender lotes exige la Ley de Planificación y Zonificación y su reglamento" (GCEM, 1948).

${ }^{15} \mathrm{El}$ artículo 57 señalaba: "Se impondrá una multa de un mil a quince mil pesos por el Ejecutivo del Estado, o privación de la libertad hasta por diez años, por la Autoridad Judicial respectiva, según la gravedad del acto" (GCEM, 1948).

${ }^{16}$ Dicha reforma señalaba que: "Se adiciona el artículo 62 del Reglamento de la Ley de Planificación y Zonificación del Estado de México, con el siguiente párrafo: Art. 62. Podrá sin embargo, darse anticipadamente la autorización para la venta de lotes, en los casos en que de acuerdo con el Gobierno del Estado, las cantidades que por concepto de pago parcial o total del precio de los mismos, sean percibidas directamente por la Institución de Crédito que el propio Gobierno designe" (GGEM, 1948).

${ }^{17}$ El artículo 10 de la LFTEM señalaba: "Los terrenos de un fraccionamiento no podrán ser objeto de promesa de venta, de venta con reserva de dominio, de venta o de cualquier otro contrato traslativo de dominio, en tanto no se concluyan las obras de urbanización y sean recibidas a entera satisfacción por el Ejecutivo del Estado" (GGEM, 1958).
} 
En los múltiples acuerdos del ejecutivo del estado que autorizaban fraccionamientos de tipo popular, se establecían las condiciones para la creación de colonias. Entre las cláusulas se señalaba que los fraccionamientos se ajustarían a las normas y lineamientos aprobados para la planificación general y lo relativo a las especificadas por la Dirección de Comunicaciones y Obras Públicas. Los requerimientos que debían cumplir los fraccionamientos tenían que ver con:

- Abastecimiento de agua potable suficiente para satisfacer las necesidades de servicios públicos y domésticos de la población que se establezca en el fraccionamiento, con una dotación mínima de doscientos litros por habitante y por día.

- Desagüe general del fraccionamiento.

- Red de distribución de agua potable.

- Red de alcantarillado.

- Tomas de agua potable y descarga de algañal (sic) en cada lote.

- Pavimento de concreto asfáltico en los arroyos de las calles.

- Guarniciones y banquetas de concreto hidráulico en las aceras de las calles.

- Alumbrado público y red de distribución de energía eléctrica domiciliaria.

- Nomenclatura de calles en placas visibles, incluyendo señalamiento vial. ${ }^{18}$

Como se puede observar, los requerimientos urbanos para los asentamientos estaban bien definidos en la planificación general del área, pero, por las condiciones que tuvieron los fraccionamientos urbanos en esa época, en la realidad eran inexistentes.

Algunos asentamientos fueron vendidos por fraccionadores privados que, aunque sabían que las tierras no eran aptas para el uso urbano habitacional y que no se iban a dotar los servicios, los vendían a migrantes que buscaban algún terreno para resolver su problema de vivienda. Recuérdese que las décadas de mayor crecimiento social en la ciudad de México fueron de los cincuenta a los setenta, lo cual impactó en la demanda de suelo

\footnotetext{
${ }^{18}$ Ejemplo de ello son los requisitos contenidos en el acuerdo del ejecutivo del estado que autoriza el fraccionamiento de tipo popular urbano y conjunto habitacional denominado Valle de Aragón, ubicado en el municipio de Nezahualcóyotl, Estado de México (GGEM, 1973).
} 
urbano y vivienda en el Estado de México y particularmente en los terrenos del ex lago de Texcoco.

La LFTEM especificaba las obligaciones de los fraccionadores, los espacios públicos que debían donar para áreas verdes y servicios públicos y hasta la latitud, de doce metros, de las vías públicas. Sin embargo, lo señalado en la ley fue contrastante con las condiciones en que se encontraban las colonias asentadas en el ex lago: sin agua, drenaje, luz y equipamiento público alguno. A pesar de que muchos fraccionadores sabían su compromiso legal, no lo cumplieron, esperaron a que las demandas de los ciudadanos presionaran al gobierno del estado para pedir que éste se hiciera cargo de los servicios e infraestructura en los asentamientos. De esta manera, la obligación de urbanización se transfirió al estado, con lo que las fraccionadoras, inmobiliarias e iniciativa privada quedaron sin responsabilidad alguna en el proceso anárquico de urbanización y en las condiciones insalubres que padecían los primeros pobladores de la zona del lago.

La reconsideración sobre la actuación de la mayoría de los fraccionadores es importante en el sentido de que ellos planificaron el área del ex vaso, marcando las colonias y las calles y haciendo obras mínimas: aplanaban calles, introducían guarniciones, construían pozos de agua o gestionaban pipas de agua para abastecer a los habitantes. El incumplimiento de las obras se dio a pesar de que los colonos pagaban los abonos y compromisos económicos de la compra del terreno; este desentendimiento de los fraccionadores contribuyó a enmarcar el abandono y pobreza que se observaba en el área urbana que se estaba formando.

El papel de las diversas instancias de gobierno reforzó esas prácticas, los asentamientos irregulares se fomentaron a través del proselitismo y apoyo partidista, ésta era una práctica que los gobiernos utilizaron en las contiendas electorales a cambio del voto; toleraban y estimulaban la invasión de tierras a cambio de apoyo electoral, actividad que se observa hasta hoy día.

De esta manera, desde las modificaciones a la LPZEM de 1948 se estableció el recurso legal en el que podían ampararse los fraccionadores de terrenos para no concluir las obras al momento de fraccionar y vender los terrenos. Es hasta 1976, con la Ley General de Asentamientos Humanos, cuando se establecen normas más sólidas para crear asentamientos humanos en todo el país. 


\section{La necesidad de vivienda y los primeros pobladores urbanos}

El espacio urbano en el área de estudio se configuró lentamente, las condiciones naturales del área, la irregularidad del suelo y la situación económica social de la población condicionó la habitabilidad de ese territorio. ${ }^{19}$ En lo que corresponde a la zona de Nezahualcóyotl, desde la década de los cuarenta los primeros pobladores se comenzaron a asentar en las orillas cercanas a la carretera México-Puebla, por supuesto de manera irregular. Una década después, ese fenómeno también se observó en la v zona en Ecatepec. Así comenzaron a surgir fraccionamientos irregulares que estaban cambiando la imagen del lugar; de un área desértica, salitrosa e inundable en época de lluvias, se pasaba a una zona con asentamientos urbanos irregulares, de alta vulnerabilidad para las edificaciones, así como focos de miseria y abandono. ${ }^{20}$

Esos asentamientos tuvieron una estrategia particular de ocupación, los primeros se ubicaron en el centro del área, dando valor con su sola existencia a los terrenos de la periferia. Las vialidades contribuyeron a la sobrevivencia y consolidación de esas poblaciones creando rutas que transportaban a la población y a los bienes de consumo inmediato: alimentos, muebles, materiales de construcción, etc. En ese sentido, las viviendas consolidaban el área en la medida en que se construían. Los primeros asentamientos humanos en Ecatepec que tuvieron la convivencia con el ex lago fueron: Granjas Valle de Guadalupe, San Agustín,

\footnotetext{
${ }^{19}$ Ayala nos ilustra al señalar que la habitabilidad tiene que ver con "las formas de habitar en una época y en un espacio determinado" (Ayala, 1999: 13); no necesariamente son las tareas para hacer agradable un espacio, sino la forma de vivir en el territorio. Reforzando lo anterior, Gerardo Sánchez subraya que la habitabilidad en la ciudad debe considerar: "1) La adecuada reproducción de quienes la habitan, al proporcionar espacios para el desarrollo de actividades vitales. 2) El pleno desarrollo de las actividades, sean éstas de tipo económico, social, cultural o de vida política. 3) Una franca relación entre habitantes, a partir de espacios que coadyuven a lograr esa interrelación no sólo de forma ocasional, sino de manera perdurable. 4) La relación con el medio ambiente al mismo tiempo de su disfrute. 5) Proteger a sus habitantes de la ocurrencia de accidentes naturales. 6) Un territorio socialmente seguro que permita a sus habitantes la realización de sus actividades sin presiones de ninguna especie. 7) Conservar su memoria histórica a partir de dar lugar a una relación entre habitantes y lo construido por generaciones que existieron en el pasado" (Sánchez, 1999: 484).

${ }^{20}$ En la década de los cuarenta comenzaron a surgir los primeros fraccionamientos urbanos en los municipios de estudio, la colonia Nuevo Laredo en el pueblo de Tultepec (1955) en Ecatepec (Bassols, 1983: 177), y en ese mismo sentido Maximiliano Iglesias señala que "desde el año de 1944 ya se habían comenzado a vender algunas extensiones de terreno ubicadas en lo que hoy es la colonia Pavón” (1978: 20) en Nezahualcóyotl.
} 
Emiliano Zapata, La Estrella y Díaz Ordaz. ${ }^{21}$ En el caso de Nezahualcóyotl, las primeras colonias fueron: Juárez Pantitlán, México, El Sol y el Barrio de Juárez Pantitlán o San Juan (García y Gutiérrez, 1999: 89). ${ }^{22}$ Es importante llamar la atención sobre quiénes definieron la traza y delimitación de los fraccionamientos urbanos y quiénes construyeron el espacio urbano. Quizá parezca que esta consideración no es importante, sin embargo, la decisión de cómo se delimitó y definió el uso del suelo repercutió en la estructura urbana de los siguientes años.

La traza general de los terrenos del ex lago tuvo su antecedente en el fraccionamiento de los terrenos en grandes manzanas prefiguradas desde la década de los treinta. Las manzanas, o superficies cuadrangulares o rectangulares, correspondían a un solo propietario, mismas que dieron origen a la dimensión de las colonias, formando un gran damero de colonias, manzanas y viviendas.

No hubo una instancia gubernamental que planeara o definiera los territorios urbanos, cada propietario de manera particular fraccionó y vendió la manzana o colonia que poseía. En algunos casos, el fraccionador marcaba los límites que tendrían las manzanas y lotes al interior de las colonias; con el auxilio de un topógrafo o agrimensor se trazaban las zonas habitacionales, calles y algunas áreas comunes, posteriormente a esa delimitación, el terreno estaba listo para su venta. ${ }^{23}$

En el afán por maximizar las ganancias por la venta de terrenos, el ex lago se fraccionó sin considerar los requerimientos de espacio para uso colectivo (escuelas, mercados, hospitales y bibliotecas) y áreas verdes (jardines, viveros y parques), de ahí las carencias y problemas urbanos que sufre el área en la actualidad. Los espacios para escuelas primarias y mercados fueron los más privilegiados, no así las áreas para salud, el esparcimiento, o áreas verdes. Algunos de los fraccionamientos habían llegado a situaciones extremas donde incluso las calles no reunían las condicio-

${ }^{21}$ Se calcula que en 1975 existían 39 fraccionamientos clandestinos en las zonas IV y v del lago de Texcoco (De la Torre, 1975: 58).

22 Aunque el decreto de creación del municipio de Nezahualcóyotl se publicó el 20 de abril de 1963 (GGEM, 1963), las autoridades ya consideraban la existencia de más de 100,000 habitantes cuando se referían a las colonias del ex vaso de Texcoco (Huitrón, 1975: 73).

${ }^{23}$ Entre las fraccionadoras más importantes que actuaron en Ecatepec se encuentran: Azteca, Ecatepec, San Agustín y Santa Clara, así como Inmobiliaria y Comercial Bustamante, Incobusa (Fracc. Jardines de Morelos) (Bassols, 1983: 185) y la Constructora Texcoco (colonia Lázaro Cárdenas). 
nes para ser transitadas. ${ }^{24}$ Así, con la promesa de que se comenzarían las obras de urbanización, los fraccionamientos se sucedían uno tras otro, al tiempo que los pobladores iniciaban la construcción social de su espacio, desde el relleno de calles para transitar, pasando por la gestión y financiamiento de pipas de agua, hasta la permanente autoconstrucción de su vivienda.

Alrededor de la década de los cincuenta, la legislatura del estado acordó autorizar fraccionamientos de tipo popular en ambos municipios, en el que se especificaban las vialidades, los servicios públicos y las áreas verdes que debía ceder las fraccionadoras a los municipios para su administración y mantenimiento. ${ }^{25}$ Sin embargo, del acuerdo en papel a la realidad de los espacios de uso colectivo, la diferencia fue evidente frente a la carencia de los mismos.

Así, para la década de los setenta, cuando comenzó la regularización del suelo, las instancias gubernamentales tuvieron pocas posibilidades para planear y destinar áreas verdes y espacios de uso colectivo a los asentamientos, ya que la mayor parte del territorio se encontraba en manos de particulares y su uso sería presumiblemente habitacional.

Son mínimos los espacios que sirven de pulmón de regeneración del medio, sólo hay pequeños parques y jardines en algunas colonias y áreas verdes que se localizan en las avenidas y en algunos lotes baldíos. El parque del pueblo y los terrenos de recuperación del lago de Texcoco forman parte de las pocas áreas verdes en la zona de estudio. ${ }^{26}$

\footnotetext{
${ }^{24}$ El caso del fraccionamiento San Agustín en la v zona de Ecatepec es un ejemplo de cómo se delimitó el espacio urbano vial, la dimensión de las calles son de aproximadamente 4 metros de ancho por lo que sólo puede transitar un vehículo a la vez.

${ }^{25}$ Algunas obligaciones de los fraccionadores eran como las indicadas para la colonia San Francisco en Ecatepec; la cláusula tercera del acuerdo de aprobación de este fraccionamiento señalaba: "La fraccionadora deberá ceder al municipio de Ecatepec, Estado de México, un área de vialidad de $8,307.00 \mathrm{~m}^{2}$ (OCHO MIL TRESCIENTOS SIETE METROS CUADRADOS). Asimismo, deberá ceder una superficie destinada a espacios verdes y servicios públicos de: $3,010.38 \mathrm{~m}^{2}$ (TRES MIL DIEZ METROS TREINTA Y OCHO DECÍMETROS CUADRADOS), estas superficies se encuentran debidamente delimitadas y marcadas en el plano aprobado" (GCEM, 1979).

${ }^{26}$ El municipio de Ecatepec posee pocos espacios de uso colectivo, entre ellos: el deportivo Morelos y la sección del Parque Estatal de la Sierra de Guadalupe (1976). Este parque se encuentra precisamente en la sierra, lejos de la planicie de la $\mathrm{v}$ zona, por lo que su acceso y comunicaciones son restringidas, motivo por el cual sólo los habitantes más cercanos a él lo visitan. En el caso del deportivo Morelos, se abrió en los años noventa y básicamente lo utiliza la población cercana al pueblo de Tulpetlac, localidad de San Carlos, y colonias circunvecinas.

Por su parte, el municipio de Nezahualcóyotl tiene el Parque del Pueblo y la Unidad Deportiva, que si bien son importantes también son insuficientes. El primero data de 1974 y la segunda de la década de los ochenta. Antonio Huitrón señala que el Parque
} 
La necesidad de vivienda de los primeros pobladores influyó en la decisión de comprar terrenos baratos e inundables en la zona del ex lago; los pobladores poco a poco fueron creando su espacio, su vivienda y patrimonio. Las autoridades, a pesar de tener instrumentos legales para planear el área, dejaron pasar la oportunidad de intervenir en una zona urbana que estaba naciendo. Los propietarios particulares y fraccionadores vieron la oportunidad de crear negocios lucrativos con o sin la anuencia de las autoridades, y en gran parte, fueron ellos quienes definieron la traza y uso urbano de esta zona. La especulación urbana del territorio del ex lago pesó más que las decisiones legislativas para planear. Así, el área de estudio se fue creando socialmente a través de un proceso de autoconstrucción de viviendas y de la cooperación vecinal para obtener los servicios urbanos básicos.

\section{Conclusiones}

En el análisis urbano de la ciudad de México se debe reflexionar en los procesos y actores específicos que intervinieron en la historia de los diversos lugares. Procesos y actores son parte de los elementos sociales que conforman la dinámica de los espacios en la ciudad, dinámica que debe ser entendida a partir de su análisis local, no de teorizaciones de fenómenos ajenos a la realidad estudiada.

El análisis del espacio está inserto en la totalidad de la estructura social, el espacio ocupa un lugar importante al ser un elemento que refleja el desarrollo de la sociedad, al tiempo que se encuentra determinado por la misma estructura social.

De esta manera, la desecación del lago de Texcoco obedecía a la necesidad imperiosa de garantizar la seguridad de la ciudad de México; así como la bonificación, deslinde y fraccionamiento de terrenos respondía, en parte, a la necesidad de espacio habitacional y vivienda de una población pobre que estaba migrando a la ciudad capital desde la década de los cuarenta.

En ese mismo sentido, el espacio urbano del lago de Texcoco lo construyeron diversos actores, cada uno de ellos expresado

del Pueblo "no se hizo ni con recursos del gobierno federal ni del gobierno del estado ni del municipio, sino que se hace con los dineros que los colonos han depositado en Fineza como pago de sus lotes" (1975: 289). El Parque del Pueblo fue planeado para albergar: una alameda, teatro al aire libre, lago artificial, zona para día de campo, zoológico, centro de convivencia infantil, área de juegos infantiles y zona para establecimientos comerciales. 
en sus acciones, tuvo un papel específico y fundamental para la desecación del lago. Los líderes de movimientos sociales, al encabezar las luchas por mejores servicios públicos; los representantes políticos, quienes hicieron lo necesario para liberar el territorio de ataduras legales destinándolo finalmente a la propiedad particular; los agentes particulares que ofrecieron servicios de agua, salud o educación; los propietarios o defraudadores de fraccionamientos, quienes no tuvieron límites para especular con el suelo y necesidad de vivienda; los pobladores o habitantes del ex lago, quienes arriesgaron su salud al vivir ahí; todos ellos participaron de diversas maneras y grados en la construcción del área urbana del ex lago de Texcoco.

Tradicionalmente, el territorio se encuentra demarcado a partir de límites administrativos que imponen los gobiernos; límites naturales que obedecen a leyes biológicas, físicas y químicas; y limites urbanos, resultado de la dinámica económica, política y social de las ciudades; sin embargo, si se considera que el territorio se transforma con la presencia del ser humano y de su hacer, entonces los espacios a través del tiempo son diferentes, ya que el hombre va transformando e influyendo en las estructuras sociales en que vive.

Así, cuando se intenta definir el espacio se debe considerar todo un proceso de valoración que parte de la materialidad que contiene ese espacio, su proceso de formación, las acciones que los seres humanos han realizado sobre su superficie, sus relaciones de apropiación, producción o vinculación con el territorio y las repercusiones económicas, políticas y sociales que vienen del exterior.

El espacio se entiende como parte integrante de la totalidad social, es productor y producto, depende de su entorno y de las acciones que en él se suceden, es resultado de cómo van cambiando las formas espaciales antiguas frente a los procesos sociales nuevos. Los procesos se adaptan a formas preexistentes y crean otras nuevas, de ahí que el espacio lacustre se trasformó poco a poco en la medida que socialmente se le intervenía.

Por estas circunstancias, la geografía urbana en el ex vaso de Texcoco en el periodo 1940-1970 tiene características específicas respecto de como la observamos hoy. En la actualidad los habitantes del área de estudio comparten, además del espacio urbano, características educativas, culturales y económicas similares, resultado de procesos parecidos de intervención política, económica y urbana; sin embargo, eso no significa que el área sea homogénea, sino que los procesos de desecación, incor- 
poración al uso urbano y ocupación social fueron similares, aunque son económica, política y socialmente diferentes.

Así, el espacio urbano de los actuales municipios de Ecatepec y Nezahualcóyotl, en parte, son expresión de esa consecución de acciones que se fueron sobreponiendo y entrelazando a través del tiempo en el territorio y que le dan un significado específico a cada área. El estudio geográfico debe considerar que el espacio es producto de un proceso histórico, de ahí lo fundamental de analizar las relaciones sociales históricas de esta área con el fin de conocer cómo se fue transformando su especificidad y cómo adquirió otra. Esto implica ver el espacio de hoy como la condensación de las condiciones, actores y procesos anteriores. El espacio urbano de los municipios de Ecatepec y Nezahualcóyotl que corresponden al ex vaso de Texcoco son resultado de la intervención de diversos actores sociales que contribuyeron desde la desecación de la cuenca de México hasta la necesidad de vivienda barata en la ciudad, dando como resultado un espacio socialmente construido y desigualmente desarrollado.

\section{Bibliografía}

Ayala-Alonso, Enrique (1999), "La transformación de la habitabilidad: génesis de la idea moderna de habitar" en Liliana Giordano y Liliana D'Angeli (eds.), El habitar. Una orientación para la investigación proyectual, Universidad de Buenos Aires-Universidad Autónoma Metropolitana, Buenos Aires, Argentina, pp. 13-21

Bassols, Mario (1983), Concentración industrial y expansión urbana en el municipio de Ecatepec, un estudio de caso en el contexto de la Zona Metropolitana de la Ciudad de México, México, Multicopias.

Calderón de la Barca, Madame (2003), La vida en México durante una residencia de dos años en ese país, México, Porrúa.

Caneda-Bernal, Antonio (1966), "Informe sobre el levantamiento topográfico del lago de Texcoco", Centro de Investigación y Documentación de Nezahualcòyotl, México.

Comisión del Valle (1862), "Carta hidrográfica del Valle de México", Catálogo de Cartogramas, Consejo de Planeación Económica y Social en el D. F., México. 
Franco, Luis G. (1948), “Comisión técnica del parque agrícola de la Ciudad de México”, en Gobierno del Distrito Federal, Glosa del periodo de gobierno del C. Gral. e Ing. Pascual Ortiz Rubio 1930-1932, Departamento del Distrito Federal, México, pp. 219-220.

Gaceta Oficial del Distrito Federal (1998), Ley orgánica de la administración pública del Distrito Federal, Cuauhtémoc Cárdenas Solórzano, jefe de gobierno del Distrito Federal-Asamblea Legislativa del Distrito Federal, 29 de diciembre, México, en <www.setravi.df.gob.mx/leyes/pdf/ ley_organica.pdf $>$, septiembre de 2004.

García-Luna, Margarita (1990), Nezahualcóyotl: tierras que surgen de un desequilibrio ecológico. Decretos relativos a los terrenos desecados del lago de Texcoco 1912-1940, México, Gobierno del Estado de México-Centro de Información y Documentación de Nezahualcóyotl, México.

García-Luna, Margarita y Pedro Gutiérrez-Arzaluz (1999), Nezahualcóyotl, monografía municipal, México, Instituto Mexiquense de Cultura-Amecrom-Gobierno del Estado.

Gobierno Constitucional del Estado de México (1931), Gaceta del Gobierno del Estado de México, 15 de abril.

Gobierno Constitucional del Estado de México (1933), Gaceta del Gobierno del Estado de México, 15 de marzo.

Gobierno Constitucional del Estado de México (1942), Gaceta del Gobierno del Estado de México, 30 de diciembre.

Gobierno Constitucional del Estado de México (1944), Gaceta del Gobierno del Estado de México, 21 octubre.

Gobierno Constitucional del Estado de México (1945), Gaceta del Gobierno del Estado de México, 1 de diciembre.

Gobierno Constitucional del Estado de México (1948), Gaceta del Gobierno del Estado de México, 15 de septiembre. 
Gobierno Constitucional del Estado de México (1948), Gaceta del Gobierno del Estado de México, 18 de septiembre.

Gobierno Constitucional del Estado de México (1958), Gaceta del Gobierno del Estado de México, 20 de diciembre.

Gobierno Constitucional del Estado de México (1963), Gaceta del Gobierno del Estado de México, 20 de abril.

Gobierno Constitucional del Estado de México (1973), Gaceta del Gobierno del Estado de México, 10 de octubre.

Gobierno Constitucional del Estado de México (1979), Gaceta del Gobierno del Estado de México, 12 de julio.

Huitrón, Antonio (1975), Nezahualcóyotl, miseria y grandeza de una ciudad, México, s/e.

Iglesias, Maximiliano (ca. 1978), Netzabualcóyotl: testimonios históricos (1944-1957), México, Servicios Educativos Populares.

Nacional Financiera-Secretaría de Hacienda y Crédito Público (1969), Proyecto Texcoco, memoria de los trabajos realizados y conclusiones, México, Nacional Financiera-Secretaría de Hacienda y Crédito Público.

Peimbert, Ángel, Luis MacGregor y Augusto Petricioli (1930), Memoria descriptiva del proyecto del Parque Agrícola de la Ciudad de México, Presentada en el Primer Congreso Nacional de Planificación, México.

Valek-Valdés, Gloria (2000), Agua, reflejo de un valle en el tiempo, México, Universidad Nacional Autónoma de México.

Valverde, Carmen y Adrián Guillermo Aguilar (1987), "Localización geográfica de la ciudad de México", en Departamento del Distrito Federal y El Colegio de México (eds.), Atlas de la ciudad de México, Departamento del Distrito Federal-El Colegio de México, México, pp. 19-22. 
Sánchez-Ruiz, Gerardo G. (1999), "Urbanización y posibilidades de la habitabilidad. La ciudad de México al fin del milenio”, en Liliana Giordano y Liliana D'Angeli (eds.), El habitar. Una orientación para la investigación proyectual, Universidad de Buenos Aires-Universidad Autónoma Metropolitana, Buenos Aires, pp. 83-486.

Sánchez-Ruiz, Gerardo G. (2002), Planificación y urbanismo de la Revolución mexicana, México, Asamblea LegislativaUniversidad Autónoma Metropolitana, Azcapotzalco.

Torre-Abedrop, Rafael de la (1975), "La tenencia de la tierra en las zonas IV y v del vaso de Texcoco", en Gobierno del Estado de México (eds.), La tenencia de la tierra (ensayos), Gobierno del Estado de México, México, pp. 55-79.

Recibido: 13 de diciembre de 2006. Reenviado: 23 de abril de 2007. Aceptado: 19 de junio de 2007.

Maribel Espinosa Castillo. Es doctora en geografía por la Universidad Nacional Autónoma de México; realizó estudios de licenciatura en sociología y maestría en planeación metropolitana en la Universidad Autónoma Metropolitana. Actualmente es investigadora nivel "C" en el Sistema Nacional de Investigadores (SNI); se desempeña como investigadora del Centro Indisciplinario de Investigaciones y Estudios sobre Medio Ambiente y Desarrollo (CIIEMAD) además de ser profesora invitada del posgrado de Ingeniería y Arquitectura Unidad Zacatenco, ambos pertenecientes al Instituto Politécnico Nacional (IPN). Sus líneas de investigación actuales son: planificación del espacio y geografía turística e industria turística y metodología de la investigación. Entre sus publicaciones destacan: "Viejas y nuevas geografías en el ex vaso de Texcoco", Investigaciones geográficas, 57, unAM, México, pp. 95-113 (2005); "Algunos problemas en la formación de investigadores y en el ejercicio de la investigación”, Quimera,1, año 7, Toluca, México, pp. 357-378 (2005); Anteproyectos de investigación turística. Metodología para su elaboración, México, Trillas (2005); Tendencias de investigación turística a principios de siglo XXI (coord.), México, IPN (2007). 